\title{
Microstructure and Mechanical Properties of Zirconia (3Y-TZP)/Zr Composites Prepared by Wet Processing and Subsequent Spark Plasma Sintering
}

\author{
Marcos Díaz ${ }^{1}{ }^{(0)}$, Anton Smirnov ${ }^{2, *}$ (D) C.F. Gutiérrez-González ${ }^{3}$, Diana Estrada ${ }^{4}$ \\ and José F. Bartolomé ${ }^{4, *(1)}$ \\ 1 UPM Laser Centre, E.T.S. Ingenieros Industriales, Universidad Politécnica de Madrid, C/José Gutiérrez \\ Abascal, 2, 28006 Madrid, Spain; marcos.diaz@upm.es \\ 2 Moscow State University of Technology "STANKIN", Vadkovsky per. 1, 127055 Moscow, Russia \\ 3 Nanoker Research S.L. Polígono Industrial de Olloniego, parcela 22 ${ }^{\mathrm{a}}$, Nave 5, Oviedo, 33660 Asturias, Spain; \\ cf.gutierrez@cinn.es \\ 4 Instituto de Ciencia de Materiales de Madrid (ICMM), Consejo Superior de Investigaciones \\ Científicas (CSIC), C/Sor Juana Inés de la Cruz 3, 28049 Madrid, Spain; dianaestradamoreno@gmail.com \\ * Correspondence: a.smirnov@stankin.ru (A.S.); jbartolo@icmm.csic.es (J.F.B.); Tel.: +7-4999-7323-70 (A.S.); \\ +34-9133-48996 (J.F.B.)
}

Received: 29 November 2019; Accepted: 11 February 2020; Published: 17 February 2020

\begin{abstract}
ZrO}_{2}$ (3Y-TZP) matrix composites with $30 \mathrm{vol} \% \mathrm{Zr}$ metallic particles were obtained by spark plasma sintering (SPS) using a colloidal processing method. The microstructure and mechanical properties of this novel ceramic-metal composite have been studied. The fracture toughness of composites is slightly higher than the values corresponding to monolithic zirconia. Scanning electron microscope (SEM) observations of the crack path show that the major contributions to toughening are the resulting crack blunting and branching that occurs at crack tips in the metallic particles before the onset of crack propagation. Plastic deformation of the metallic particles is strongly influenced by the constraint induced by the different phase arrangements. This system can be considered as a particulate composite with a periodic residual stress field, in which the metal phase is under strong compression due to the residual thermal stresses as a consequence of the coefficient of thermal expansion mismatch. Therefore, the plastic deformation of the metallic particles in this composite is likely to be reduced to a large extent.
\end{abstract}

Keywords: wet processing route; ceramic-metal composites; spark plasma sintering (SPS); microstructure; mechanical properties

\section{Introduction}

Zirconia (3Y-TZP) is an extensively used material for many structural and biomedical applications due to its excellent biocompatibility, chemical inertness and good tribological and mechanical performance [1-4]. However, the major limitation of zirconia-based ceramics is still their low fracture toughness. Brittle ceramics can be toughened by introducing a ductile phase into them. When second phase metallic particles are incorporated into a brittle matrix, there are several toughening mechanisms that may operate, but the maximum benefit is derived from the plastic deformation of the metallic particles, i.e., crack blunting and bridging an advancing crack [5-7]. The bridging ligaments exert closure stresses, which reduce the stress intensity at the crack tip and offer resistance to further crack opening or propagation.

The magnitude of these crack closure stresses on the crack wake is based upon a stress-strain relation of the metal ligaments, which is influenced by the properties of the reinforcing metal itself and 
the constraint (i.e., ligament yield stress, diameter, orientation, inclusion volume fraction and the nature of the ceramic/metal interface) [8-10]. Unfortunately, the addition of micrometric metallic particles can lead to the significant degradation of strength and fatigue resistance [11]. The difficulty with fabricating a truly homogeneous ceramic-metal composite lies in achieving the required dispersion and spatial distribution of the phases at different scales. Commercial approaches to producing these composites involve dry powder metallurgical techniques, yielding a discrete metal phase dispersed in an otherwise homogeneous ceramic matrix material [12]. Therefore, these routes suffer from a lack of control of the microstructure. Homogeneous dispersion of metallic powders in ceramic powders can be very hardly attained on account of their different density. On the other hand, the dimension of the metallic particles is usually limited to those of the commercially available metallic powders. Consequently, for the fabrication of reliable and multifunctional ceramic-metal composites, the ability to control the fraction and structure (dispersion, size distribution, geometry, interface, etc.) of both phases is mandatory, and this can be achieved by following a wet processing route. In previous works [12-14], the behavior of ceramic-metal particulate suspensions was studied to adjust their rheological parameters in order to attain the stability that leads to homogeneous compacts. It has been demonstrated that with optimal conditions (appropriate selection of solids loading and surfactant addition) is possible to form a network that trapped the metal particles and thus to avoid its segregation in order to obtain reproducible microstructures free of agglomerates with the metal particles homogeneously distributed in the final compacts after sintering. Using this concept, new biocomposites (biocermets) have been designed and fabricated with some interesting properties. Several studies on zirconia that has been reinforced with biometals such as titanium [15,16], niobium [17-20] and tantalum [21,22], have been reported in the literature. However, the study of the zirconia-zirconium composite system has been very scarce, and only a few papers have been published. Virkar et al. [23] prepared by hot-pressing in Ar mixtures of zirconium oxide-zirconium 2-phase alloys powders with a composition of 40 at $\%$ $\mathrm{Zr}-60$ at \% O (23 vol \% metal phase). Complete densification occurred in $3 \mathrm{~h}$ at $1873 \mathrm{~K}$. Microstructural examination revealed that the oxide grains were completely isolated from each other by a thin film of the metal phase. During investigations into the mechanical properties of $\mathrm{Zr}-\mathrm{ZrO}_{2-\mathrm{x}}$ composites, the metal did not wet the oxide grain boundaries in the range of the stability of the tetragonal polymorph of zirconia, and after a long annealing treatment the solid metal was expelled from the composite. Since the furnace atmosphere was reducing to $\mathrm{ZrO}_{2-x}$, the loss of metallic zirconium from the bulk must have occurred by the exudation of zirconium, undoubtedly by solid-state diffusion. Therefore, the mechanical properties (fracture strength and Young's elastic modulus) of these ceramic-metal composites were not improved [24].

Spark plasma sintering (SPS) has become a popular technique for ceramic-metal consolidation [25-29]. Its prominent feature is to pass a direct current (DC) through the small graphite die that contains the ceramic-metal powders. These powders can be consolidated to high density in a much-shortened sintering time: a typical SPS cycle takes less than a few minutes, relative to hours for hot-press or conventional sintering, indicating the high efficiency of SPS. On the other hand, it is a powerful route to prevent the oxidation of the metals components and minimizing two-phase reactions.

Zirconium was selected as a metal second phase because of its biocompatibility, low electrochemical potential, high corrosion resistance and mechanical engineering properties. Zirconium (density $=6520 \mathrm{Kg} / \mathrm{m}^{3}$; melting point $=2127 \mathrm{~K}$ ) has a tensile strength of about $330 \mathrm{MPa}$, yield strength of $230 \mathrm{MPa}$ and Young's modulus of $95 \mathrm{GPa}$ at $20{ }^{\circ} \mathrm{C}$ [30]. Many studies demonstrate excellent biocompatibility of zirconium in a variety of situations including orthopedic and dental applications [31].

The aim of this paper was the fabrication of a new zirconia (3Y-TZP)-Zr composite by a wet processing route and subsequent SPS. The microstructure and mechanical properties of this novel ceramic-metal composite have been studied. 


\section{Experimental Procedures}

\subsection{Starting Materials}

The following commercially available powders have been used as raw materials: (1) Tetragonal zirconia polycrystals (3Y-TZP, $3 \mathrm{~mol} \% \mathrm{Y}_{2} \mathrm{O}_{3}$; TZ-3YE, Tosoh Corp.), with an average particle size of $\mathrm{d}_{50}=0.26 \pm 0.05 \mu \mathrm{m}$, a Brunauer, Emmett and Teller (BET) specific surface area of $16 \pm 3 \mathrm{~m}^{2} / \mathrm{g}$. (2) Zirconium (Sigma-Aldrich, $99.2 \%$ purity) with an average particle size $\mathrm{d}_{50}=5.65 \pm 0.15 \mu \mathrm{m}$.

\subsection{Powder Processing}

Zirconia/Zr slurries with a solid load of $70 \mathrm{wt} \%$ were prepared using pentanol as liquid media with 70/30 proportion (in vol \%) of zirconia (3Y-TZP) and zirconium. The mixture was homogenized by milling with zirconia balls in polyethylene containers at $150 \mathrm{rpm}$ during $24 \mathrm{~h}$ and then dried at $333 \mathrm{~K}$ during $12 \mathrm{~h}$. The use of pentanol prevents any further potential oxidation of $\mathrm{Zr}$ particles during ball-milling homogenization as a consequence of the protection loss of the passive film onto their surface by wear. The resulting powders were ground in an agate mortar and subsequently passed through a $100 \mu \mathrm{m}$ sieve. The obtained powders were placed in a die-punch setup made from isostatic graphite (grade C4, DonCarb Graphite, Rostov, Russia) and compacted by spark plasma sintering (SPS, FCT Systeme GmbH, HP D-25 SD, Effelder-Rauenstein, Germany) following this procedure: (i) The samples were heated from room temperature to $873 \mathrm{~K}$ at a rate of $600 \mathrm{~K} / \mathrm{min}$, using a pressure of 10 MPa; (ii) From $873 \mathrm{~K}$ to $1373 \mathrm{~K}$ a heating rate of $200 \mathrm{~K} / \mathrm{min}$ and a pressure of $10 \mathrm{MPa}$ was used; (iii) From $1373 \mathrm{~K}$ to $1573 \mathrm{~K}$ a heating rate of $50 \mathrm{~K} / \mathrm{min}$ and pressure of $80 \mathrm{MPa}$ was used, and this final temperature and pressure were maintained for one minute. The temperature is controlled using a central pyrometer focusing on the bottom of a borehole inside the upper punch, $5 \mathrm{~mm}$ above the top of the sintering compact. This guarantees a correct temperature measurement, independent of the sample properties or size.

The sintering cycle was performed under vacuum conditions. The sintered specimens had diameters of 20 and $50 \mathrm{~mm}$ and a thickness of 2-4 mm in order to obtain machined specimens for the flexural strength and toughness determination, respectively (Section 2.4). For comparison, zirconia powders were densified by SPS following the same sintering cycle.

\subsection{XRD Characterization}

X-ray diffractometry (XRD) analyses of these samples were carried out in a D8 diffractometer (Bruker AXS Inc., Madison, WI, USA) using CuK $\alpha$ radiation $(\lambda=1.5405981 \AA)$ working at $40 \mathrm{kV}$ and $30 \mathrm{~mA}$ in a step-scanning mode with a step size of $0.01^{\circ}$ and a scan speed of $0.06^{\circ} / \mathrm{min}$ at diffraction angles $2 \theta$ ranging from $20^{\circ}$ to $70^{\circ}$. Analyses of the crystal phases were found using the following ICSD codes: $62,994\left(\mathrm{t}-\mathrm{ZrO}_{2}\right), 41,572\left(\mathrm{~m}-\mathrm{ZrO}_{2}\right)$ and 43,700 (zirconium).

The monoclinic phase content of different surfaces was calculated from $27^{\circ}$ to $33^{\circ}$ using the Garvie and Nicholson method [32].

$$
X_{m}=\frac{I_{m}(111)+I_{m}(\overline{1} 11)}{I_{m}(111)+I_{m}(\overline{1} 11)+I_{t}(101)}
$$

where $I_{t}$ and $I_{m}$ represent the integrated intensity (area under the peaks) of the tetragonal (101) $t_{t}$ and monoclinic $(111)_{\mathrm{m}}$ and $(-111)_{\mathrm{m}}$ peaks. The monoclinic volume fraction was then obtained using the equation proposed by Toraya et al. [33].

$$
V_{m t o t}=\frac{1.311 X_{m}}{1+0.311 X_{m}}
$$




\subsection{Microstructural Characterization}

The microstructure of the sintered specimens was studied by scanning electron microscopy (SEM, Phenom G2, The Netherlands) on surfaces polished down to $1 \mu \mathrm{m}$ with diamond paste using a polishing machine RotoPol-22 (Struers, Copenhagen, Denmark) at a speed of $150 \mathrm{rpm}$ and a force of $30 \mathrm{~N}$. The zirconia specimens were thermally etched at $1523 \mathrm{~K}$ for $30 \mathrm{~min}$. To measure the zirconia average grain size, a linear intercept method (LIM) was used [34].

\subsection{Mechanical Characterization}

The Vickers hardness, Hv, was measured using a Vickers diamond indenter (Leco 100-A, St. Joseph, MI, USA) on polished surfaces, with an applied load of $9.8 \mathrm{~N}$, and with an indentation time of $10 \mathrm{~s}$. The magnitude of the Vickers hardness was determined according to,

$$
\mathrm{Hv}=1.854 \mathrm{P} / \mathrm{d}^{2}
$$

where $P$ is the applied load (in $\mathrm{N}$ ) and $d$ is the diagonal length (in $\mathrm{mm}$ ).

The sizes of the corresponding indentations were determined by scanning electron microscopy. The hardness results were averaged over 10 indentations per specimen of each composition. The density of the compacts was measured according to the Archimedes method [21].

Fracture toughness was measured by the single edge notched beam (SENB) technique on machined specimens (five of each composition) with dimensions of $3.0 \times 4.0 \times 45 \mathrm{~mm}^{3}$. The tests were performed at room temperature using a $5 \mathrm{kN}$ universal testing machine AutoGraph AG-X (Shimadzu Corp., Tokyo, Japan) at a crosshead speed of $0.5 \mathrm{~mm} / \mathrm{min}$ with span $40 \mathrm{~mm}$. Notch was introduced by using a diamond blade (saw). This method and formulas for fracture toughness calculations were reported elsewhere [21].

Biaxial flexural strength was measured by using the piston-on-3-ball method (ISO 6872 standard). A disc of the material to be tested ( $\varnothing 20 \mathrm{~mm}$, thickness $1.3-1.5 \mathrm{~mm}$ ) was placed upon three balls sitting $120^{\circ}$ apart on a $10 \mathrm{~mm}$ diameter circle, with the polished surface as the tensile face. The piston directly applied the load to the unpolished face at the center of the circle defined by the three balls. The experiments were performed at room temperature using the same testing device applied for toughness determination, with a piston speed of $1 \mathrm{~mm} / \mathrm{min}$ until failure occurred. To obtain the average strength and elastic modulus, twelve specimens of each composition were tested. Details of calculation procedures have been reported in previous works [22].

\section{Results and Discussion}

\subsection{XRD Study}

Figure 1 shows typical X-ray diffraction patterns in the $2 \theta$ range from $20^{\circ}$ to $70^{\circ}$ for polished surfaces of monolithic 3Y-TZP and 3Y-TZP/Zr composites. As it can be observed, the monolithic zirconia (Figure 1A) is fully tetragonal, whereas in the case of the zirconia/Zr composite a small amount of monoclinic zirconia can be seen (Figure 1B). The peaks of Zr metal are clearly distinguished. No other phases are detected, as would be expected due to the chemical compatibility of both components at the processing temperature. However, it should be noted that the zirconium peaks are shifted towards lower values of $2 \theta$, or in terms of interplanar distance, higher $\mathrm{d}$ spacing values in comparison with the reference pattern (ISCD code: 43700). 

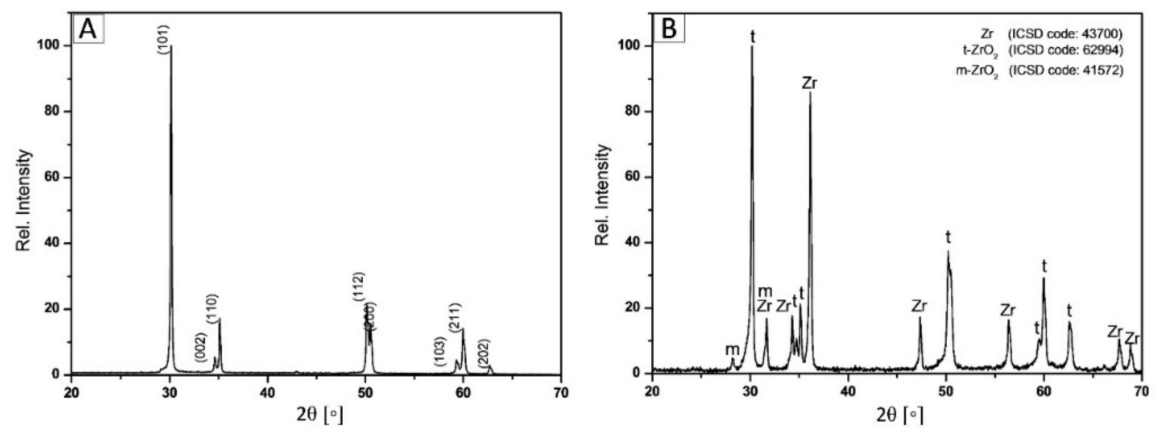

Figure 1. X-ray diffractometry (XRD) patterns of monolithic 3Y-TZP ceramic (A), and 3Y-TZP/Zr composite (B) sintered by spark plasma sintering (SPS) at $1573 \mathrm{~K}$.

An average increasing in d spacing of $0.0216 \AA$ (approximately $2.8 \%$ ) is observed, which indicates that zirconium particles are under a strong compressive residual stress field, which is induced during cooling from the sintering temperature due to the coefficient thermal expansion (CTE) mismatch between $\mathrm{t}-\mathrm{ZrO}_{2}\left(\alpha=10.8 \times 10^{-6} \mathrm{~K}^{-1}\right)$ and $\mathrm{Zr}\left(\alpha=5.8 \times 10^{-6} \mathrm{~K}^{-1}\right)$. Thus, when these composites cool down from the sintering temperature, the reinforcement contracts less than the matrix; the metal particles are subjected to compressive stress, and residual tensile stresses are accumulated in the zirconia matrix. Therefore, the effects of the residual stress due to this CTE mismatch between $3 Y$-TZP and $\mathrm{Zr}$ have to be taken into consideration in relation to the transformability of $\mathrm{t}-\mathrm{ZrO}_{2}$. Generally, the phase transformation is promoted by an applied stress, and the transformation rate increases with the stress.

When the residual tensile stress is imposed on $\mathrm{t}-\mathrm{ZrO}_{2}$ grains, phase transformation can occur easily with aid of the stress, which explains the appearance of the (11-1) peak corresponding to monoclinic zirconia in the XRD pattern of composite (Figure 1B).

The calculation of the average thermal residual stresses induced both in the zirconia matrix and zirconium particles has been carried out by applying the formulation developed by Taya et al. [35], based on the modified Eshelby's model. Since the fraction of porosity in $3 \mathrm{Y}-\mathrm{TZP} / \mathrm{Zr}$ composites is very small ( $\approx 2$ vol $\%$ ), the simplified equations proposed by Taya et al. for composites without voids have been used. The following input parameters have been employed:

The volume fraction of zirconium particles, $f_{Z r}(0.3)$; Poisson's coefficients and Young's moduli of zirconia matrix and zirconium, $v_{\mathrm{ZrO}_{2}}(0.23) / v_{\mathrm{Zr}}(0.34)$ and $E_{\mathrm{Zr}}(95 \mathrm{GPa}) / E_{\mathrm{ZrO}_{2}}(200 \mathrm{GPa})$ respectively, and the CTE misfit strain, $\alpha^{*}$, which has been calculated by integrating with respect to temperature from $1573 \mathrm{~K}$ (the sintering temperature) to $298 \mathrm{~K}$ (room temperature) and using $\alpha_{\mathrm{Zr}}=5.8 \times 10^{-6} \mathrm{~K}^{-1}$ and $\alpha_{\mathrm{ZrO}_{2}}=10.8 \times 10^{-6} \mathrm{~K}^{-1}$ [35]. The calculated average thermal residual stresses in the particulate, $<\sigma>_{\mathrm{Zr}}$, and in the $\mathrm{ZrO}_{2}$ matrix, $<\sigma>_{\mathrm{ZrO}_{2}}$ are

$$
\begin{array}{r}
<\sigma>_{\mathrm{Zr}}=-870 \mathrm{MPa} \\
<\sigma>_{\mathrm{ZrO}_{2}}=373 \mathrm{MPa}
\end{array}
$$

Therefore, the tensile stress fields in the vicinity of the zirconium grains promote the spontaneous transformation of 3Y-TZP particles from the tetragonal phase to the monoclinic phase.

The obtained results from the Equations (1) and (2) showed that in the monolithic 3Y-TZP only $1 \mathrm{vol} \%$ of the available tetragonal zirconia transformed to monoclinic symmetry during failure (Table 1 ). Meanwhile, in the 3Y-TZP/Zr composites, it went only $2 \mathrm{vol} \%$ with an initial $11 \mathrm{vol} \%$ in the polished ceramic-metal composites. 
Table 1. Densities and mechanical properties of all studied specimens, as well as volume fractions of tetragonal " $\mathrm{t}$ " and monoclinic " $\mathrm{m}$ " zirconia in polished and fractured surfaces and the resulting transformability of tetragonal zirconia.

\begin{tabular}{|c|c|c|c|c|c|c|c|c|c|c|}
\hline \multirow{3}{*}{ Specimen } & \multirow{3}{*}{$\begin{array}{l}\text { Density } \\
{[\% t h]}\end{array}$} & \multirow{3}{*}{$\begin{array}{c}\text { Young's } \\
\text { Modulus } \\
\text { E [GPa] }\end{array}$} & \multirow{3}{*}{$\begin{array}{l}\text { Flexural } \\
\text { Strength } \\
\sigma_{f}[\mathrm{MPa}]\end{array}$} & \multirow{3}{*}{$\begin{array}{l}\text { Hardness } \\
H V \text { [GPa] }\end{array}$} & \multirow{3}{*}{$\begin{array}{c}\text { Fracture } \\
\text { Toughness } K_{I c} \\
{\left[\mathrm{MPa} \cdot \mathrm{m}^{1 / 2}\right]}\end{array}$} & \multicolumn{4}{|c|}{$\begin{array}{c}\text { Volume Fractions } \\
\text { of } \mathrm{t} \text { - and } \mathrm{m}-\mathrm{ZrO}_{2} \text { [vol\%] }\end{array}$} & \multirow{3}{*}{$\begin{array}{c}\text { Transformability } \\
\text { of } \mathrm{t}-\mathrm{ZrO}_{2} V_{\text {trans }}\end{array}$} \\
\hline & & & & & & \multicolumn{2}{|c|}{ Polished } & \multicolumn{2}{|c|}{ Fractured } & \\
\hline & & & & & & $t$ & $\mathrm{~m}$ & $t$ & $\mathrm{~m}$ & \\
\hline $\mathrm{ZrO}_{2}$ & 99 & $199 \pm 4$ & $1071 \pm 99$ & $14.4 \pm 0.3$ & $3.8 \pm 0.1$ & 99 & 1 & 98 & 2 & 1 \\
\hline $\mathrm{ZrO}_{2} / \mathrm{Zr}$ & 98 & $166 \pm 5$ & $825 \pm 63$ & $12.8 \pm 0.2$ & $4.1 \pm 0.1$ & 89 & 11 & 87 & 13 & 2 \\
\hline
\end{tabular}

\subsection{Microstructure Study}

An electron micrograph of the $\mathrm{ZrO}_{2}-\mathrm{Zr}$ composite is shown in Figure 2A. In this micrograph, the darker and bright phases are zirconia and zirconium grains, respectively. A duplex grain size distribution of zirconium particles is observed. Wet processing of zirconia and zirconium powders using pentanol as the liquid medium allows obtaining compacts wherein the zirconium particles are uniformly dispersed in the matrix, without the presence of large agglomerates of metal or ceramic particles. It is known concerning the capability of alcohols to electrostatically stabilize suspensions containing small ceramic particles by the formation of an electrical double layer with a net negative charge on the particle surface [36-39]. The mechanisms proposed to explain the electrical double layer formation in organic liquid media are based upon donor-acceptor interactions between particle surface and organic liquid [36]. In the case of amphoteric oxides, like titania or zirconia, which have a point of zero charge $(\mathrm{PZC}) \approx 6[40,41]$, the mechanism proposed by Damodaran and Mougdil [42] to explain the surface charge of oxide particles and electrical double layer formation in alcoholic media can be summarized in the following steps: (1) The adsorption of two alcohol molecules on the oxide particle surface; (2) the ionization and formation of $\mathrm{RO}^{-}$and $\mathrm{ROH}_{2}{ }^{+}$; (3) capture of $\mathrm{H}^{+}$from the oxide surface by $\mathrm{RO}^{-}$; (4) and the desorption of $\mathrm{ROH}$ and $\mathrm{ROH}_{2}{ }^{+}$. Zeta potential measurements show that the values become less negative as the molecular size of the alcohol increases, due to their dielectric constant decreasing, and therefore, their tendency to ionization on the surface also diminishes. On the other hand, the adsorption of generated $\mathrm{ROH}_{2}{ }^{+}$increases for alcohols with larger molecular size, which partially neutralizes the surface negative charge [39]. Thus, alcohol having smaller molecular size, like methanol, should form more easily the electrical double layer and yield more stable suspensions. However, Farrokhi-rad et al. [39] found out the opposite behavior for the series methanol, ethanol, isopropanol and butanol, the methanolic suspension being the less stable. In order to explain this result, Farrokhi-rad et al. took into account the effect of the viscosity of different alcohols on the diffusion coefficient given by the Stokes-Einstein equation [43], which is directly related with the tendency of particles to form agglomerates:

$$
D=\frac{k_{b} T}{6 \pi \eta r}
$$

where $k_{b}$ is Boltzmann's constant, $T$ is absolute temperature, $r$ is the particle radius and $\eta$ is the viscosity of the medium. Since, generally speaking, the zeta potential of ceramic particles is low in pure alcohols, these can diffuse more rapidly and increase the frequency of collisions with each other due to Brownian motion in a medium with low viscosity, and as a consequence, the formation of agglomerates is favored. In the case of pentanol used in this study, the viscosity $\left(3.619 \times 10^{-3} \mathrm{~Pa} \cdot \mathrm{s}\right)$ [44], is higher than those of the alcohols above mentioned. Thus, although a low charge on the particles is expected (assuming than the surface of both ceramic, $\mathrm{ZrO}_{2}$ and passivated $\mathrm{Zr}$ particles are chemically similar), the higher viscosity decreases the diffusion as well as the tendency to the formation of large and hard agglomerates. On the other hand, the adsorption of pentanol molecules, which have larger molecular size, onto the surface of particles does not rule out, as it was mentioned before. 

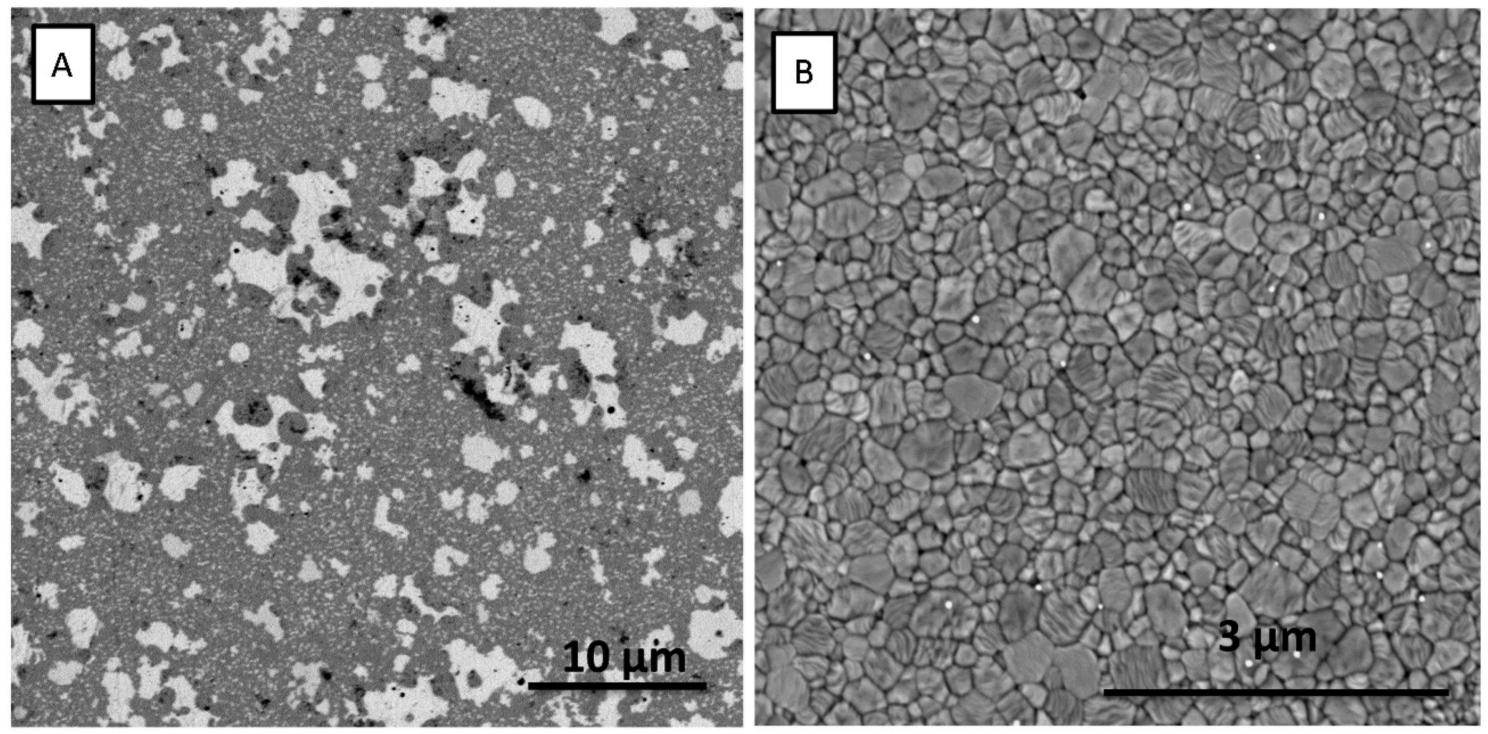

Figure 2. SEM micrographs of a polished surface of the zirconia-zirconium composite (A) (ceramic matrix: dark; zirconium particles: bright) and a thermally etched monolithic zirconia (B).

This would create a steric hindrance that contributes to avoiding collisions between particles that can yield hard agglomerates. Hence, the pentanolic $\mathrm{ZrO}_{2} / \mathrm{Zr}$ suspension prepared in this work, with a high solid load (70 wt \%), can be considered as a partially stabilized one with weak interparticle forces that can create easily breakable particle networks, which avoid the segregation by sedimentation of the larger size fraction of $\mathrm{Zr}$ particles during drying, and prevent the formation of hard agglomerates. Consequently, microstructures with the metal phase homogeneously dispersed, without large agglomerates, which can act in a detrimental way for mechanical properties, and with a continuous ceramic/metal concentration ratio are obtained.

SEM micrograph of the polished and subsequently thermally etched surface of zirconia ceramic is shown in Figure 2B. It is important to mention that after thermal etching no difference has been found between the ceramic matrix grain sizes of the 3Y-TZP and 3Y-TZP/Zr composites. According to LIM the zirconia average grain size for monolithic zirconia and composite is about 0.32 and $0.29 \mu \mathrm{m}$, respectively. Consequently, the presence of the zirconium particles has not affected the grain growth of zirconia.

\subsection{Mechanical Properties}

The mean biaxial flexural strength, Young's modulus, hardness and fracture toughness for the studied specimens are presented in Table 1. The Young's moduli of the composite were found to be close to values predicted by the rule of mixtures of Voigt and Reuss models. Considering $\mathrm{E}_{\mathrm{ZrO} 2}=200 \mathrm{GPa}$ and $\mathrm{E}_{\mathrm{Zr}}=95 \mathrm{GPa}$ [30], the prediction from these models is $169 \mathrm{GPa}$. These values are reasonably close to the experimental ones $(\approx 166 \mathrm{GPa})$, taking into account that a small fraction of porosity $(\approx 2 \%)$ is present.

The mean biaxial flexural strength values corresponding to $\mathrm{ZrO}_{2}$ and $\mathrm{ZrO}_{2} / \mathrm{Zr}$ were found to be $1071 \pm 99 \mathrm{MPa}$ and $825 \pm 63 \mathrm{MPa}$, respectively. As a direct consequence of the smaller critical grain size in $\mathrm{ZrO}_{2}$, the bending strength of the monolithic ceramic is higher than the strength corresponding to zirconia/metal composites. On the other hand, it is important to point out, the apparent increase in strength due to the transformation-induced compressive stresses on the surface of the composites. The average fracture toughness of $\mathrm{ZrO}_{2} / \mathrm{Zr}$ composites was found to be $4.1 \mathrm{MPa} \cdot \mathrm{m}^{1 / 2}$, slightly higher than the value obtained for the monolithic zirconia $\left(3.8 \mathrm{MPa} \cdot \mathrm{m}^{1 / 2}\right)$. The modest monolithic zirconia toughness value can be explained by the low transformation of zirconia during fracture. 
The hardness value observed for $\mathrm{ZrO}_{2} / \mathrm{Zr}$ composites was $12.8 \mathrm{GPa}$ (Table 1). This value is higher than that expected from the rule of mixtures (Voigt model) [45], which is given by

$$
H_{\text {comp }}=f_{\mathrm{ZrO}_{2}} \cdot \mathrm{H}_{\mathrm{ZrO}_{2}}+f_{\mathrm{Zr}} \cdot \mathrm{H}_{\mathrm{Zr}}
$$

where $f_{\mathrm{ZrO}_{2}}, \mathrm{H}_{\mathrm{ZrO}_{2}}, f_{\mathrm{Zr}}$, and $\mathrm{H}_{\mathrm{Zr}}$ denote volume fractions and hardness of the ceramic matrix and $\mathrm{Zr}$ particles, respectively. By taking $\mathrm{H}_{\mathrm{ZrO}_{2}}=14.4 \mathrm{GPa}$ from Table 1, and $\mathrm{H}_{\mathrm{Zr}}=1.5 \mathrm{GPa}$ [30], then Equation (6) yields a hardness value of $10.5 \mathrm{GPa}$. Thus, the measured hardness is $\approx 22 \%$ higher than the value expected by the rule of mixtures. This fact could be related to hardness increasing of zirconium particles due to the compressive residual stresses to which they are subjected [46].

Fractographic studies of the materials showed no clear evidence of bridging and plastically deformed zirconium particles and matrix-reinforcement interfacial decohesion (Figure 3). Fracture of the $\mathrm{Zr}$ particles occurred predominantly by cleavage. The compressive stress in the metal particles produces that the crack is only attracted by the particle and generates the crack trapping by the ductile phase. This was attributed mainly to the constraint imposed by the rigid matrix and residual stresses surrounding the metal particles.

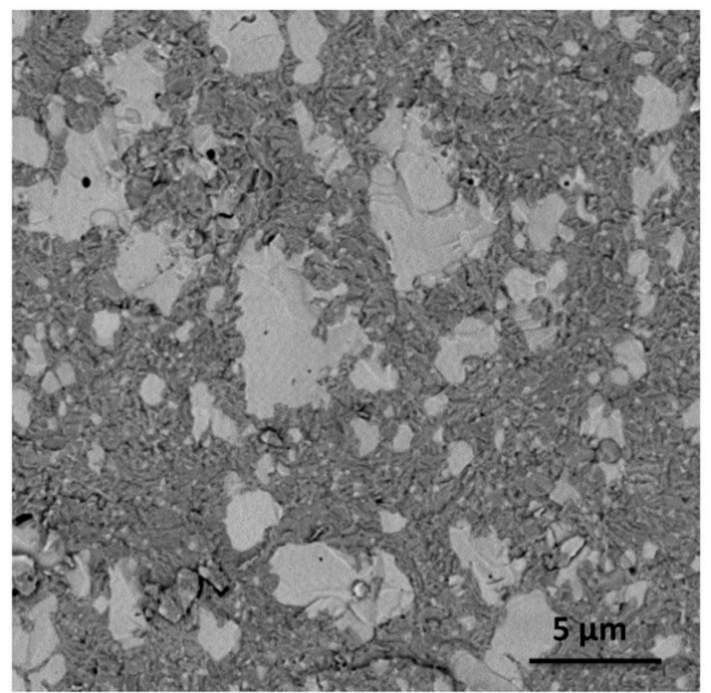

Figure 3. Fracture surface of $\mathrm{ZrO}_{2} / \mathrm{Zr}$ composite obtained by SPS after the bending test.

On the other hand, if the strength of the ceramic-metal bond is too strong, then there will be no debonding, and the particle will be almost fully constrained, giving little opportunity for plastic stretching. In this particular case, the irregularly shaped zirconium particles are mechanically interlocked with the matrix. The perfect bonding imposes lateral constraints on the inclusions, prohibiting the full advantage of the particle's ductility. As pointed out in Ashby et al. [47], the force-displacement curve for a bonded (constrained) particle is quite different than that for an unconstrained material, as measured in an ordinary tensile test. The degree of constraint is an important factor affecting the amount of energy absorbed in stretching, thus the fracture toughness.

Figure 4 shows the SEM image of crack microstructure details along the path of a crack produced by a Vickers indentation. SEM observations on crack paths suggest the occurrence of both crack-tip blunting and renucleation by zirconium grains as operating toughening mechanisms in these composites. The crack can be arrested at the $\mathrm{Zr}$ phase particle, such that it must renucleate on the other side. Consequently, the stress reduction at the crack-tip becomes the primary source of the increased fracture toughness. 


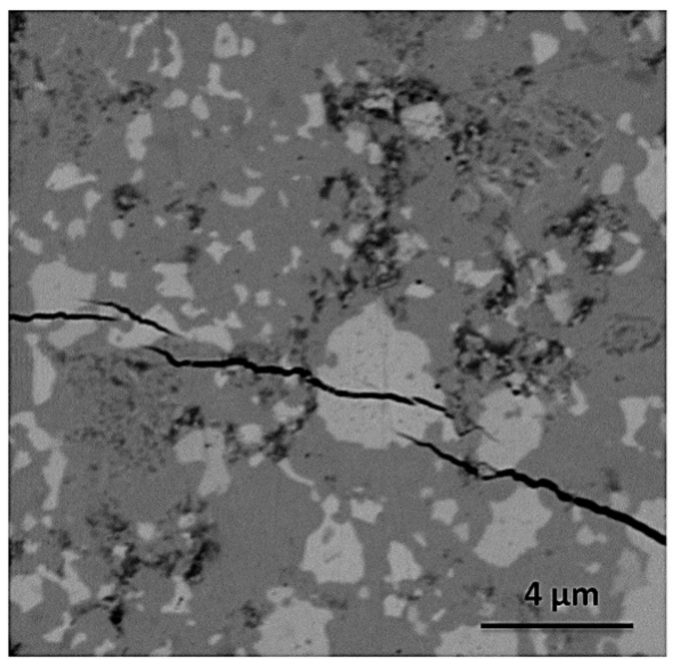

Figure 4. SEM image of crack microstructure details along the path of a crack produced by a Vickers indentation.

$\mathrm{XRD}$ analyses of the polished surfaces of monolithic zirconia materials revealed the predominance of $\mathrm{t}-\mathrm{ZrO}_{2}$ (Table 1). Additionally, the results proved that the fraction of transformed zirconia slightly increases during the fracture process (Table 1). It can be concluded that SPS zirconia has no presence of any transformation toughening mechanism. This may be attributed to the nanoscale nature of the zirconia grains, below the critical transformation size. On the other hand, it was found that the high $\mathrm{t} \rightarrow \mathrm{m}$ transformation in the polished ceramic-metal composites (11\%), together with its low $\mathrm{t} \rightarrow \mathrm{m}$ transformability ( $2 \%)$. Thus, the zirconia transformability in the studied materials is not relevant for the increase of the average fracture toughness.

The results obtained in this investigation suggest that toughness mechanisms associated with ductile phases and operating under crack propagation are very sensitive to plastic properties (yield stress) of the reinforcement. This property plays a very important role in the crack growth resistance of these $\mathrm{ZrO}_{2} / \mathrm{Zr}$ composites. In the case of the $\mathrm{Zr}$ particle constrained in a zirconia matrix the threshold to plastic deformation is much higher than in the case of more ductile metal like $\mathrm{Nb}$ or Ta particles reinforced a zirconia matrix [17-22]. Therefore, the crack-tip energy was not used to plastically deform the metal particles, as in the case of the $\mathrm{ZrO}_{2} / \mathrm{Nb}$ or $\mathrm{ZrO}_{2} / \mathrm{Ta}$ composite. The crack propagation resistance in the $\mathrm{ZrO}_{2} / \mathrm{Zr}$ composites can be attributed to crack-particle interaction intrinsic mechanisms, including crack renucleation (in the matrix and/or particle), crack branching or crack blunting. Thus, the bridging of metal reinforcements may not be a universally effective method in improving the crack growth resistance of zirconia ceramics, and depends on the intrinsic properties of the metal reinforcement, and also of the extrinsic properties like the nature of the interfaces between the dissimilar materials, constrain of the metal particle and residual stress distribution in the ceramic-metal system. On the other hand, in these particular composites with limited plastic deformation of the metal particles, there is a way to avoid the conflicts between the mutually exclusive properties of toughness and fatigue resistance present in other zirconia-metal ceramic systems [11] through the presence of toughening mechanisms that results in a local decrease of stress at the crack-tip. Further investigations will focus on how these intrinsic toughening mechanisms analyzed in this study affect the fatigue mechanical behavior of zirconia/zirconium composites.

\section{Conclusions}

The wet processing method and the Spark Plasma Sintering (SPS) technique have been used to obtain zirconia/Zr compacts with high densities ( $98 \%$ of the theoretical density) and microstructures with uniformly distributed metallic particles. 
No clear evidence of bridging as the main reinforcement mechanism by the plastic deformation of zirconium particles has been observed. This can be related to the constraint of metal particles due to the large compressive thermal stress field to which they are subjected, together with the strong bonding with the rigid ceramic matrix, which avoid the plastic stretching of metal particles.

The dominant toughening mechanisms operating in the present $\mathrm{ZrO}_{2}-\mathrm{Zr}$ composite are crack blunting and branching, which were strictly limited to the increases of the composite's toughness value.

Author Contributions: Conceptualization, M.D., J.F.B.; methodology, C.F.G.-G., D.E.; supervision, J.F.B.; validation, A.S.; writing-original draft, A.S., M.D., J.F.B. All authors have read and agreed to the published version of the manuscript.

Funding: We would like to thank the Ministry of Science and High education of the Russian Federation for supporting this work under contract No. 074-11-2018-011.

Conflicts of Interest: The authors declare no conflict of interest.

\section{References}

1. Kameo, K.; Friedrich, K.; Bartolome, J.F.; Diaz, M.; Lopez-Esteban, S.; Moya, J.S. Sliding wear of ceramics and cermets against steel. J. Eur. Ceram. Soc. 2003, 23, 2867-2877. [CrossRef]

2. Bartolome, J.F.; Montero, I.; Diaz, M.; Lopez-Esteban, S.; Moya, J.S. Accelerated aging in 3-mol\%-yttria-stabilized tetragonal zirconia ceramics sintered in reducing conditions. J. Am. Ceram. Soc. 2004, 12, 2282-2285. [CrossRef]

3. Smirnov, A.; Kurland, H.-D.; Grabow, J.; Müller, F.A.; Bartolome, J.F. Microstructure, mechanical properties and low temperature degradation resistance of $2 \mathrm{Y}-\mathrm{TZP}$ ceramic materials derived from nanopowders prepared by laser vaporization. J. Eur. Ceram. Soc. 2015, 35, 2685-2691. [CrossRef]

4. Soon, G.; Pingguan-Murphy, B.; Lai, K.W.; Akbar, S.A. Review of zirconia-based bioceramic: Surface modification and cellular response. Ceram. Inter. 2016, 42, 12543-12555. [CrossRef]

5. Rodriguez-Suarez, T.; Bartolome, J.F.; Moya, J.S. Mechanical and tribological properties of ceramic/metal composites: A review of phenomena spanning from the nanometer to the micrometer length scale. J. Eur. Ceram. Soc. 2012, 32, 3887-3898. [CrossRef]

6. Moya, J.S.; Diaz, M.; Gutierrez-Gonzalez, C.F.; Diaz, L.A.; Torrecillas, R.; Bartolomé, J.F. Mullite-refractory metal (Mo, Nb) composites. J. Eur. Ceram. Soc. 2008, 28, 479-491. [CrossRef]

7. Rodriguez-Suarez, T.; Lopez-Esteban, S.; Bartolome, J.F.; Moya, J.S. Mechanical properties of alumina-rich magnesium aluminate spinel/tungsten composites. J. Eur. Ceram. Soc. 2007, 27, 3339-3344. [CrossRef]

8. Bartolome, J.F.; Beltran, J.I.; Gutierrez-Gonzalez, C.F.; Pecharromán, C.; Muñoz, M.C.; Moya, J.S. Influence of ceramic-metal interface adhesion on crack growth resistance of $\mathrm{ZrO}_{2}-\mathrm{Nb}$ ceramic matrix composites. Acta Mater. 2008, 56, 3358-3366. [CrossRef]

9. Bartolome, J.F.; Diaz, M.; Moya, J.S. Influence of the metal particle size on the crack growth resistance in mullite-molybdenum composites. J. Am. Ceram. Soc. 2002, 85, 2778-2784. [CrossRef]

10. Bartolome, J.F.; Diaz, M.; Moya, J.S.; Saiz, E.; Tomsia, A.P. Mullite/Mo interfaces formed by intrusion bonding. J. Eur. Ceram. Soc. 2004, 24, 785-790. [CrossRef]

11. Smirnov, A.; Beltrán, J.I.; Rodriguez-Suarez, T.; Pecharromán, C.; Muñoz, M.C.; Moya, J.S.; Bartolomé, J.F. Unprecedented simultaneous enhancement in flaw tolerance and fatigue resistance of zirconia-Ta composites. Sci. Rep. 2017, 7, 44922. [CrossRef] [PubMed]

12. Diaz, M.; Bartolome, J.F.; Requena, J.; Moya, J.S. Wet processing of mullite/molybdenum composites. J. Eur. Ceram. Soc. 2000, 20, 1907-1914. [CrossRef]

13. Pecharroman, C.; Lopez-Esteban, S.; Bartolome, J.F.; Moya, J.S. Evidence of nearest-neighbor ordering in wet-processed zirconia-nickel composites. J. Am. Ceram. Soc. 2001, 84, 2439-2441. [CrossRef]

14. Smirnov, A.; Peretyagin, P.; Bartolome, J.F. Processing and mechanical properties of new hierarchical metal-graphene flakes reinforced ceramic matrix composites. J. Eur. Ceram. Soc. 2019, 39, 3491-3497. [CrossRef]

15. Fernandez-Garcia, E.; Gutierrez-Gonzalez, C.F.; Fernandez, A.; Torrecillas, R.; Lopez-Esteban, S. Processing and Spark Plasma Sintering of zirconia/titanium cermets. Ceram. Inter. 2013, 39, 6931-6936. [CrossRef] 
16. Gutierrez-Gonzalez, C.F.; Smirnov, A.; Bartolome, J.F. Aging effect on the tribological behavior of a novel 3Y-TZP/Nb biocomposite against ultra high molecular weight polyethylene. J. Am. Ceram. Soc. 2012, 95, 851-854. [CrossRef]

17. Fernandez-Garcia, E.; Guillem-Martí, J.; Gutierrez-Gonzalez, C.F.; Fernandez, A.; Ginebra, M.P.; Esteban, L. Osteoblastic cell response to spark plasma-sintered zirconia/titanium cermets. J. Biomater. 2014, 29, 813-823. [CrossRef]

18. Bartolomé, J.F.; Moya, J.S.; Couceiro, R.; Gutierrez-Gonzalez, C.F.; Guitián, F.; Martínez-Insua, M. In vitro and in vivo evaluation of a new zirconia/niobium biocermet for hard tissue replacement. J. Biomater. 2016, 76, 313-320. [CrossRef]

19. Smirnov, A.; Gutierrez-Gonzalez, C.F.; Bartolomé, J.F. Cyclic fatigue life- and crack-growth behavior of zirconia-niobium composites. J. Am. Ceram. Soc. 2013, 96, 1709-1712. [CrossRef]

20. Gutierrez-Gonzalez, C.F.; Moya, J.S.; Palomares, F.J.; Bartolomé, J.F. Low-temperature aging degradation-free 3Y-TZP/Nb composites. J. Am. Ceram. Soc. 2010, 93, 1842-1844. [CrossRef]

21. Smirnov, A.; Bartolomé, J.F. Microstructure and mechanical properties of $\mathrm{ZrO}_{2}$ ceramics toughened by 5-20 vol\% Ta metallic particles fabricated by pressureless sintering. Ceram. Int. 2014, 40, 1829-1834. [CrossRef]

22. Smirnov, A.; Bartolomé, J.F. Mechanical properties and fatigue life of $\mathrm{ZrO}_{2}-\mathrm{Ta}$ composites prepared by hot pressing. J. Eur. Ceram. Soc. 2012, 32, 3899-3904. [CrossRef]

23. Virkar, A.V.; Johnson, D.L. Fracture behavior of $\mathrm{ZrO}_{2}-\mathrm{Zr}$ composites. J. Am. Ceram. Soc. 1977, 60, 514-519. [CrossRef]

24. Virkar, A.V.; Johnson, D.L. Wetting Characteristics of $\mathrm{Zr}$ with $\mathrm{ZrO}_{2-\mathrm{x}}$. J. Am. Ceram. Soc. 1977, 60, 85. [CrossRef]

25. Smirnov, A.; Peretyagin, P.; Bartolomé, J.F. Wire electrical discharge machining of 3Y-TZP/Ta ceramic-metal composites. Alloys Compd. 2018, 739, 62-68. [CrossRef]

26. Esteban-Tejeda, L.; Smirnov, A.; Prado, C.; Moya, J.S.; Torrecillas, R.; Bartolomé, J.F. Multifunctional ceramic-metal biocomposites with Zinc containing antimicrobial glass coatings. Ceram. Int. 2016, 42, 7023-7029. [CrossRef]

27. Smirnov, A.; Volosova, M.; Peretyagin, P.; Bartolomé, J.F. Tribological behaviour of a 3Y-TZP/Ta ceramic-metal biocomposite against ultrahigh molecular weight polyethylene (UHMWPE). Ceram. Int. 2018, 44, 1404-1410. [CrossRef]

28. Mishina, H.; Tomoki, K.; Ikegami, H.; Ohishi, R.; Hase, A. Mechanical and biotribological properties of ceramic-metal composites (TiC/Ti-15Mo and SiC/Ti-15Mo) for joint prostheses and the effects of additive metallic elements of W, Nb, and Ir. Mater. Sci. Eng. A. 2012, 549, 38-42. [CrossRef]

29. Thomson, K.E.; Jiang, D.; Yao, W.; Ritchie, R.O.; Mukherjee, A.K. Characterization and mechanical testing of alumina-based nanocomposites reinforced with niobium and/or carbon nanotubes fabricated by spark plasma sintering. Acta Mater. 2012, 60, 622-632. [CrossRef]

30. Miracle, D.B.; Donaldson, S.L. (Eds.) ASM Handbook, 10th ed.; ASM International: Cleveland, OH, USA, 2001.

31. Mehjabeen, A.; Song, T.; Wei, X.; Ping, H.; Qian, T.; Qian, M. Zirconium alloys for orthopaedic and dental applications. Adv. Eng. Mat. 2018, 20, 1800207. [CrossRef]

32. Garvie, R.C.; Nicholson, P.S. Phase analysis in zirconia systems. J. Am. Ceram. Soc. 1972, 55, $303-305$. [CrossRef]

33. Toraya, H.; Yoshimura, M.; Somiya, S. Calibration curve for quantitative analysis of the monoclinic tetragonal $\mathrm{ZrO}_{2}$ system by X-ray diffraction. J. Am. Ceram. Soc. 1984, 67, 119-121.

34. Wurst, J.C.; Nelson, J.A. Lineal intercept technique for measuring grain size in two-phase polycrystalline ceramics. J. Am. Ceram. Soc. 1972, 55, 109. [CrossRef]

35. Taya, M.; Hayashi, S.; Kobayashi, A.S.; Yoon, H.S. Toughening of a particulate-reinforced ceramic-matrix composites by thermal residual stress. J. Am. Ceram. Soc. 1990, 73, 1382-1391. [CrossRef]

36. Siffert, B.; Jada, A.; Eleli Letsango, J. Location of the shear plane in the electrical double layer in an organic medium. J. Colloid. Interf. Sci. 1994, 163, 327-333. [CrossRef]

37. Menon, M.; Decourcelle, S.; Ramousse, S.; Halvor Larsen, P. Stabilization of ethanol-based alumina suspensions. J. Am. Ceram. Soc. 2006, 89, 457-464. [CrossRef]

38. Widegren, J.; Lennart Bergström, L. The effect of acids and bases on the dispersion and stabilization of ceramic particles in ethanol. J. Eur. Ceram. Soc. 2000, 20, 659-665. [CrossRef] 
39. Farrokhi-rad, M.; Ghorbani, M. Stability of titania nano-particles in different alcohols. Ceram. Int. 2012, 38, 3893-3900. [CrossRef]

40. Heijman, S.G.J.; Stein, H.N. Electrostatic and steric stabilization of $\mathrm{TiO}_{2}$ dispersions. Langmuir 1995, 11, 422-427. [CrossRef]

41. Moreno, M.; Requena, J.; Moya, J.S. Slip Casting of Yttria-Stabilized Tetragonal Zirconia Polycrystals. J. Am. Ceram. Soc. 1988, 71, 1036-1040. [CrossRef]

42. Damodaran, R.; Mougdil, B.M. Electrophoretic deposition of calcium phosphates from non-aqueous media. Colloids Surf. A: Physicochem. Eng. Aspects. 1993, 80, 191-195. [CrossRef]

43. Chandrasekar, S. Stochastic problems in physics and astronomy. Rev. Mod. Phys. 1943, 15, 1-89. [CrossRef]

44. Lide, D.R. Handbook of Chemistry and Physics, 85th ed.; CRC Press: Boca Raton, FL, USA, 2004.

45. Kim, H.S. On the rule of mixtures for the hardness of particle reinforced composites. Materials Science and Engineering A. 2000, 289, 30-33. [CrossRef]

46. Raceanu, L.; Optasanu, V.; Montesin, T.; Montay, G.; Francois, M. Shot-peening of pre-oxidized plates of zirconium: Influence of residual stress on oxidation. Oxid. Met. 2013, 79, 135-145. [CrossRef]

47. Ashby, M.F.; Blunt, F.J.; Bannister, M. Flow characteristic of highly constrained metal wires. Acta. Metall. 1989, 37, 1847-1857. [CrossRef]

(C) 2020 by the authors. Licensee MDPI, Basel, Switzerland. This article is an open access article distributed under the terms and conditions of the Creative Commons Attribution (CC BY) license (http://creativecommons.org/licenses/by/4.0/). 